\title{
Consider the Kirtland's Warbler
}

\author{
Daniel L. Dustin and Keri A. Schwab \\ Department of Parks, Recreation, and Tourism \\ College of Health \\ University of Utah \\ 250 South 1850 East Room 200 \\ Salt Lake City, Utah 84112-0920 \\ (801)-585-7560 \\ daniel.dustin@health.utah.edu \\ Please direct all correspondence to Daniel L. Dustin
}

\begin{abstract}
This paper challenges the conventional wisdom of departments of parks and recreation taking sport management under their "wing." Based on a review of the sport management literature and a polling of sport management and park and recreation educators, we argue that departments of parks and recreation are but temporary refuges for migratory sport management programs that eventually will want to build their own "nests." Efforts to accommodate sport management only serve to undermine the mission of academic programs in parks and recreation by sapping resources, compromising the education of park and recreation majors, and eroding park and recreation faculty members' sense of professional purpose.
\end{abstract}

KEYWORDS: Sport management, park and recreation education, student numbers, academic mission, professional purpose

There is an old saying to the effect that the railroads collapsed because they thought they were in the railroad business when they really were in the transportation business. Might the same be said someday of our academic field; that it collapsed because we thought we were in the park and recreation education business when we really were in the student numbers business?

This is the risk we appear to be taking when we oppose departments of parks and recreation taking on sport management. If we really are in the student numbers business, then we are likely jeopardizing our future by not accommodat- 
ing the growing interest in sport management. But what if we are in the park and recreation education business after all? Might we then be jeopardizing our future by welcoming sport management into the fold?

We have thought long and hard about how best to characterize this conundrum and how best to discuss going or not going "there" with respect to sport management. That thought process took the first author back 30 years to the University of Michigan's School of Natural Resources and some lessons learned about an endangered songbird called the Kirtland's warbler.

\section{The Plight of the Kirtland's Warbler}

The Kirtland's warbler is a rare member of the wood warbler family. The male's summer plumage is a bright yellow colored breast streaked with black and bluish gray back feathers, a dark mask over its face with white eye rings, and a bobbing tail. The male's song is loud, yet low pitched, ending with an upward inflection. Overall, the bird is less than six inches long.

The Kirtland's warbler is endangered for a number of reasons, not the least of which is its highly specific habitat requirements. Restricted in the summer months to a handful of counties in northern Michigan, Wisconsin and the Province of Ontario, Canada, the Kirtland's warbler builds its nest on the ground in grasses beneath the branches of young jack pine trees. Sufficient stands of such trees spring forth only as a consequence of fire, as jack pines require the heat from fires to open their cones, release their seeds, and prepare the ground for germination. The soil requirements are also highly specific. The Kirtland's warbler nests would be washed away by rainstorms was it not for the highly porous Grayling sand that allows water to percolate quickly into the ground.

Typically, male Kirtland's warblers arrive at their summer habitat from the Bahamas a few days before the females, establish and defend their territories, and then court the females upon their arrival. The females build the nests and the males bring food. This relationship continues through the breeding season, which results in four to five cream-white eggs speckled and blotched with brown. After the 13 to 16 day incubation period, the chicks are hatched and both parents feed them for approximately five weeks while the fledglings remain in the undergrowth beneath the jack pine branches.

Enter the brown-headed cowbird, also known as the "buffalo bird." Cowbirds used to follow the vast herds of bison roaming the Great Plains, feasting on insects that swarmed around the hooves of the grazing bison. Unable to maintain a stationary nest with such a migratory lifestyle, the brown-headed cowbird developed the habit of laying its eggs in the nests of other obliging birds and then leaving the incubation up to them. The cowbird chicks hatch earlier than most songbirds, are more aggressive, and tend to out-compete their nest mates for food. This reduces the number of non-cowbird young that survive.

As the forests across middle America were cut back over time, the brownheaded cowbird's habitat expanded eastward. Eventually, it overlapped with that of the Kirtland's warbler, creating yet another threat to the survivability of the 
yellow-breasted songbird. The likelihood of any of those four to five cream-white eggs speckled and blotched with brown surviving in a nest shared with the hardier brown-headed cowbird eggs was diminished dramatically. Indeed, studies have shown that when one cowbird egg is laid in a warbler nest, only one to three warbler chicks may survive. If two cowbird eggs are laid and hatched in a warbler's nest, none of the warbler chicks survive.

\section{Looking for Answers}

The questions we would have you ponder are these: Is park and recreation education the "Kirtland's warbler," and is sport management the "brown-headed cowbird?" Are departments of parks and recreation providing "nests" for transitory sport management programs? Are we "feeding" sport management students at the expense of our own park and recreation students? And finally, by hosting sport management programs are we, too, in danger of contributing to our own extinction?

To answer these questions we contacted a cross-section of sport management educators throughout the United States as well as park and recreation educators who have taken sport management under their "wing."' We inquired about the origins of sport management, the preferred academic home for sport management, and what the future of sport management might hold. We also surveyed the sport management literature to get a better sense of what is being written about this "nesting" issue. Finally, we organized the responses to our questions in a way that can be discussed in terms similar to those describing the plight of the Kirtland's warbler.

\section{The Migration Question}

Sport management is a relative newcomer to higher education. Ohio University is frequently credited with offering the first program in 1966 (Mason, Higgins \& Owen, 1981), and the roots of sport management are clearly in physical education. Indeed, for many years "sport management programs were primarily physical education curricula with a sport management title" (Pitts, 2001, p. 6). But as some physical education departments began to move away from teacher education and pedagogy toward kinesiology, sport management's academic leaders found it necessary to begin searching for a more accommodating home (McDonald, 2006).

While some sport management programs remained in physical education (e.g., West Virginia University), many others migrated to sport studies (e.g., University of Louisville), business (e.g., University of Massachusetts), and recreation (e.g., University of Illinois). This diversity of academic "nests" can be explained by specific institutional circumstances as well as the ambiguity surrounding the nature

\footnotetext{
This paper is based, in part, on conversations with sport management and park and recreation faculty from the following institutions: Bowling Green State University, Clemson Universiry, Florida International University, Florida State University, Georgia Southern University, North Carolina State University, Slippery Rock State University, Temple University, West Virginia University, University of Florida, University of Illinois, University of Louisville, University of Massachusetts, University of Oregon, University of the Pacific, University of Texas, and the University of Utah.
} 
of sport management's body of knowledge, curricular content, and professional orientation. Sport management is commonly defined as "management theory and practice specifically related to sport, exercise, dance, and play as these enterprises are pursued by all sectors of the population" (NASSM, 1986, p. 1). This definition brings sport management in close proximity to a variety of other academic fields of study and raises questions about their relatedness. Hardy (1987), for example, asked, "Where does sport management end and recreation administration begin?" (p. 6).

For recreation's part, the upsurge of interest in sport management has coincided with a general decline in park and recreation student numbers, McDonald, C. (2006); Wellman, D. (2006); Wolff, R. (2006). The conventional wisdom has it that if sport management looks like a close relation to parks and recreation, then perhaps it can be adopted without having to change too much in the way of curricular offerings. Furthermore, it is clear to many park and recreation educators that the majority of sport management students end up working in park and recreation settings anyway, McDonald, C. (2006); Wellman, D. (2006); Wolff, R. (2006). Perhaps sport management is merely a variation on the traditional park and recreation theme?

\section{The Incubation Question}

In the last decade, departments of parks and recreation have increasingly served as obliging, if not begrudging, hosts to sport management. While some universities have allocated additional resources to support sport management programs nested in departments of parks and recreation (e.g., North Carolina State University), others have not (e.g., Florida International University). ${ }^{2}$ This has led to several challenges. For example, park and recreation educators who have little knowledge of, or expertise in, sport management often end up being the primary professors of sport management students (Mahony, Mondello, Hums, \& Judd, 2004). This frequently results in a fundamental disconnect between professor and student. The park and recreation educator struggles to come up with sportrelated content while sport management students struggle to make the connection between what they perceive to be park and recreation principles and practices and their application to sport settings. Neither party feels particularly well-served.

In some instances, park and recreation educators have welcomed sport management based on the assumption that general principles of management and marketing can be conveyed to sport management as well as park and recreation majors in a seamless manner Wolff, R. (2006). Yet sport management and park and recreation majors typically see themselves as having very different professional identities. Consequently, while their professors may not see the meshing of park

\footnotetext{
${ }^{2}$ North Carolina State University's Department of Parks, Recreation, and Tourism Management has been given new faculty lines to support sport management. Florida International University (FIU), on the other hand, has received no new lines. Meanwhile, as much as $85 \%$ of the sport management curriculum at FIU is taught by park and recreation educators. In essence, the sport management "curriculum" is the leisure services management curriculum.
} 
and recreation and sport management curricula as problematic, their students frequently do and their sense of academic community is diminished accordingly. ${ }^{3}$

This mixing of sport management and park and recreation students leads to yet another concern. How distinctive is sport management as an academic field of study? Chalip (2006) framed the question thusly,

If the study of sport management is to position itself as a distinctive discipline, then it must take seriously the possibility that there are distinctive aspects to the management of sport. In other words, if sport management is to be anything more than the mere application of general marketing principles to the sport context, then there must be something about sport that renders distinctive concerns, foci, or procedures when sport is managed. (p. 3)

Chalip and others (Pitts, 2001; Zakrajsek, 1993; Chelladurai, 1992) have been inclined to define what they do as distinct and unique and therefore worthy of its own "nest."

Based on our conversations with sport management educators and a review of their literature, it appears the ultimate goal is a free standing degree program. The push is for independence, Mondello, M. (2006). Pitts (2001) championed this point of view when she stated,

Lastly, in relation to credibility, I want to touch on a topic that I believe affects our credibility. It's a topic that has hounded us for many years-where should sport management be housed? The discussion almost always centers around the question of placing sport management either in departments of physical education or recreation, or in a school of business. Why box ourselves in? I propose that sport management should be in its own house. We have been hard at work building that house and its foundation and deserve to move in anytime now. In other words, we should be our own department or school. (p. 8)

Chalip (2006) echoed these sentiments. "Our field has come a long way in a short time. We are ready to find our distinctive relevance" (p. 16). Zakrajsek (1993) drove the point home by concluding, "sport management is unique, has a place in the sun, and ought to cast its own shadow" (p. 6).

We can infer from these comments that a "nest" in departments of parks and recreation is seen by sport management educators as but a temporary arrangement. What we offer is shelter for a migrating "bird." To paraphrase Chelladurai (1992), we, parks and recreation, are but co-opted partners in their (sport management's) pursuits (p. 217). Chalip (2006) underscored this perspective when he said, "the subtext in the debate over our best home is really about academic status, not ontological necessity" (p. 2). Costa (2005) made a similar point when discussing the

\footnotetext{
'Heightening the challenge is the popularity of sport management as an academic home for athletes, Majoring in something akin to their primary life interest is appealing and athletes flock to sport management. This is problematic for two reasons. First, many athletes are marginal students. They attend college because it is a farm system for their sport. They see their college experience primarily as preparation for an athletic career. Consequently, they relegate academic coursework to the back burner. Second, even athletes who are diligent about their studies are frequently whisked away from the classroom at inopportune times for practice and competitions. This distupts the continuity of their classroom experience. Their professors, meanwhile, are advised to make the best of a bad situation.
} 
results of her Delphi Study on the future of sport management. She reported that sport management's preferred homes are either in business or sport studies. In weighing the relative advantages of each, Costa concluded, "There are, of course, differences in the academic prestige accorded to colleges of business on the one hand, and departments of sports studies (e.g., kinesiology) on the other" (pp. 131132). When it comes to academic prestige, departments of parks and recreation are not even part of the conversation.

In sum, locating sport management in departments of parks and recreation is largely a matter of convenience-at least from sport management's perspective. It does not arise out of "ontological necessity." The current residence will do until a better home comes along. Yes, we may all agree that departments of parks and recreation benefit from a temporary boost in student credit hour production by housing sport management, but at what cost?

\section{The Extinction Question}

There is nothing inherently wrong with a fledgling academic field like sport management wanting to flap its own wings. But in our case, the concern should be the lasting negative impact that temporarily hosting sport management will have on our departments of parks and recreation. To the extent we shift resources to accommodate increasing student demand for sport management, retool our faculty so they relate better to sport management students and their career interests, and modify our curricular offerings to make them more relevant to sport settings, we are doing damage to our own park and recreation students, faculty, and profession. ${ }^{4}$ We are jeopardizing our future by trying to accommodate something we are not. We are, like the Kirtland's warbler, running the risk of extinction because of our accommodating nature.

\section{A Faustian Bargain?}

The optimists among us trust this can work out in a manner that will benefit both park and recreation education and sport management. They point to Chelladurai (1992), for example, who distinguished between the management of participant sport and spectator sport.

The appendage sport to both forms of endeavor seems to mask the fundamental differences between the two spheres of activity. These differences become clear if we consider them as the provision of human services in sport versus the provision of entertainment services through sport. The human services are those services whereby we change our clients in some meaningful way-to be fitter, healthier,

\footnotetext{
${ }^{4}$ According to Dr. Lawrence Allen, Dean of the College of Health, Education, and Human Development at Clemson University, accreditation of academic programs promises to be yet another contentious issue. Currently, departments of parks and recreation wishing to be accredited by the National Recreation and Park Association (NRPA), and offering but one degree with multiple concentrations, must ensure that all their student majors meet NRPA accreditation standards. This includes sport management students. What will happen if and when the North American Society for Sport Management (NASSM) demands that those same students meet NASSM accreditation standards to gain entry into the sport management field?
} 
more skilled, and so on. In the other equally significant class of services, we are involved with the entertainment services, where the focus is on the spectators.

These are two drastically different enterprises. Their target populations are different, their personnel requirements are different, and the recognition and status afforded to each are different. That is why significant differentiation is occurring in the management of these two domains. (p. 218)

From this depiction of sport management as having a two-pronged professional focus, it would appear that departments of parks and recreation are much better suited for preparing students for the management of participant sport rather than spectator sport. Perhaps the field of sport management will break in two at some point; the half focusing on "human services" gravitating toward departments of parks and recreation (e.g., Clemson University) and the half focusing on "entertainment services" gravitating toward schools of business (e.g., University of Oregon). The problem with this prospect is that most sport management students are interested in the entertainment services side of sport, not the human services side. They are not interested in human services per se-the heart of what our field has been, is, and, hopefully, will always be about.

\section{Conclusion}

And so the debate is egged on. Should we or should we not go "there" with respect to sport management? For some park and recreation departments, the debate is over. Sport management is already an entrenched offering. For others, there is still time for careful consideration. In that regard, perhaps we can learn one final lesson from the plight of the Kirtland's warbler. In an effort to protect this endangered species from itself, the songbird's guardians have taken a variety of proactive measures to safeguard its environs and curtail the outside forces jeopardizing its continued health and welfare. Chief among those proactive measures has been the removal of brown-headed cowbirds from the Kirtland's warbler habitat.

\section{References}

Chalip, L. (2006). Toward a distinctive sport management discipline. Joumal of Sport Management, 20, 1.21 .

Chelladurai, P. (1992). Sport management: Opportunities and obstacles. Joumal of Sport Management, $6,215-219$.

Costa, C. (2005). The status and future of sport management: A Delphi study. Joumal of Sport Man. agement, 19, 117-142.

Hardy, S. (1987). Graduate curriculums in sport management: The need for a business orientation. Quest, 39, 207-216.

Mahony, D.; Mondello, M.; Hums, M; and Judd, M. (2004). Are sport management doctoral programs meeting the needs of the faculty job market? Observations for today and the future. Journal of Sport Management, 18, 91-110.

Mondello, M. (2006). Personal conversation. Isport management professor, Florida State Universityl.

North American Society for Sport management. (1986). Article II. Constitution, p. I.

Parks, J. and Olafson, G. (1987). Sport management and a new journal. Joumal of Sport Management, $1,1.3$. 
Pitts, B. (2001). Sport management at the millennium: A defining moment. Joumal of Sport Management, 15, 1-9.

Wellman, D. (2006). Personal conversation. [Chair, Department of Parks, Recreation, and Tourism Management, North Carolina State Universityl.

Wolff, R. (2006). Personal conversation. Associate Dean, College of Education, and Interim Chair, Department of Health, Physical Education and Recreation, Florida International University].

Zakrajsek, D. (1993). Sport management: Random thoughts of one administrator. Journal of Sport Management, 7, 1-6. 